\title{
Mechanical Feed-Forward Loops Contribute to Idiopathic Pulmonary Fibrosis
}

Margaret A.T. Freeberg, ${ }^{*}$ Apostolos Perelas, ${ }^{*}$ Jane K. Rebman, ${ }^{*}$ Richard P. Phipps, ${ }^{\dagger}$ Thomas H. Thatcher, ${ }^{*}$ and Patricia J. Sime

From the Division of Pulmonary Disease and Critical Care Medicine, ${ }^{*}$ Virginia Commonwealth University, Richmond; and Independent Scholar, ${ }^{\dagger}$ Henrico, Virginia

\author{
Accepted for publication \\ September 8, 2020. \\ Address correspondence to \\ Patricia J. Sime, M.D., Virginia \\ Commonwealth University, \\ 1101 East Marshall St., Sanger \\ Hall 1-030, Richmond, \\ VA 23298. E-mail: patricia. \\ sime@vcuhealth.org.
}

\begin{abstract}
Idiopathic pulmonary fibrosis is a progressive scarring disease characterized by extracellular matrix accumulation and altered mechanical properties of lung tissue. Recent studies support the hypothesis that these compositional and mechanical changes create a progressive feed-forward loop in which enhanced matrix deposition and tissue stiffening contribute to fibroblast and myofibroblast differentiation and activation, which further perpetuates matrix production and stiffening. The biomechanical properties of tissues are sensed and responded to by mechanotransduction pathways that facilitate sensing of changes in mechanical cues by tissue resident cells and convert the mechanical signals into downstream biochemical signals. Although our understanding of mechanotransduction pathways associated with pulmonary fibrosis remains incomplete, recent progress has allowed us to begin to elucidate the specific mechanisms supporting fibrotic feed-forward loops. The mechanosensors discussed here include integrins, Piezo channels, transient receptor potential channels, and nonselective ion channels. Also discussed are downstream transcription factors, including myocardin-related transcription factor and Yes-associated protein/transcriptional coactivator with PDZ-binding motif. This review describes mechanosensors and mechanotransduction pathways associated with fibrosis progression and highlights promising therapeutic insights. (Am J Pathol 2021, 191: 18-25; https:// doi.org/10.1016/j.ajpath.2020.09.008)
\end{abstract}

Idiopathic pulmonary fibrosis (IPF) is a progressive scarring disease of the lung with a life expectancy shorter than that of lung cancer. ${ }^{1-3}$ It is characterized in part by the accumulation of extracellular matrix (ECM) proteins in the interstitial space and impaired gas exchange, thereby decreasing lung function. The ECM composition in the lung plays an important role in regulating cell behavior and function.

Wolff's law, proposed in 1892, states ${ }^{4}$ : "Every change in the form and function of bone or of their function alone is followed by certain definite changes in their internal architecture, and equally definite alteration in their external conformation, in accordance with mathematical laws." The law defines that bone adapts and optimizes strength in response to the loads under which it is placed. Although the principle of mechanical adaptation is most obvious with muscle and bones, ${ }^{5}$ all tissues adapt to the mechanical loads they are under, including the lung. ${ }^{6}$
Structure-function relationships can be observed by differences in ECM architecture and are accompanied by distinct mechanical properties in anatomic compartments of the lung. ${ }^{7-9}$ It experiences several principal mechanical forces. It is under pressure from inhaled air, and it is subjected to cyclic tensile stretching with respiration cycles, as well as to the stiffness of the underlying ECM. These forces are sensed by fibroblasts that synthesize and modify the ECM to structurally stabilize the tissue and shield other cells

Supported in part by NIH grants R01HL127001 and R01HL133761, and by the Chandler-Pollock-Solimano-Thomas Pulmonary Fibrosis Research Fund.

Disclosures: P.J.S. is a paid consultant for Boehringer Ingelheim, UCB, and Three Lakes Foundation, serves on the board of the American Thoracic Society, the scientific council of the Parker Francis Foundation, an advisory board for Galecto, and the medical scientific advisory committee for the Pulmonary Fibrosis Foundation, receives grant funding from the NIH, and holds patents related to fibrosis. 
from mechanical stimulation. ${ }^{10}$ In healthy lung tissue, this is a homeostatic process involving synthesis, modification, and degradation of matrix, collectively called matrix remodeling. In pathologic conditions, an imbalance in this process can lead to many pathologies, including increased ECM stiffness (fibrosis), decreased elasticity (emphysema), and airway remodeling (asthma). The imbalanced matrix buildup in fibrosis creates a self-fulfilling feed-forward loop of enhanced matrix deposition and stiffening. ${ }^{11}$

Recent and ongoing work in IPF supports the hypothesis that diseased matrix is both a consequence and a driver of fibrosis. $^{12-14}$ IPF is characterized by accumulation of fibroblasts and myofibroblasts within fibroblastic foci, deposition and cross-linking of the ECM, and dysregulation of proteases. Cumulatively, this action results in a buildup of ECM, increased stiffness (loss of compliance), thickened alveolar septae, and impairment of gas exchange, leading to progressive dyspnea, supplemental oxygen dependence, and eventually death. This stiffened matrix changes the forces sensed by fibroblasts, which drive myofibroblast differentiation, expression and cross-linking of ECM proteins, and other profibrotic effector functions, leading to a progressive feed-forward loop centered on the matrix mechanics. ${ }^{11,13}$

Current therapeutic options slow the progression of IPF but do not halt or reverse the scarring in the lung. ${ }^{15}$ Given the role of the ECM in the initiation and progression of fibrosis, therapeutic strategies that target the matrix or cellular mechanical sensing may be an essential target to combine with current therapeutic options. The current review describes how lung fibroblasts sense and respond to mechanical stresses, as well as how altered mechanical properties of the fibrotic lung drive the progression of fibrosis. Possible therapeutic insights are also discussed.

\section{The ECM of the Lung and Mechanical Changes in IPF}

The matrix is bioactive and plays a role in the progression of IPF as a regulator of cellular phenotype and behavior. In the lung, the ECM is composed of a basement membrane with thin sheets of glycoproteins and the interstitial matrix, creating a fiber network that provides structure and the bulk of the mechanical integrity of the tissue. ${ }^{16}$ The ECM contains $>300$ different proteins, including collagens, proteoglycans, and glycoproteins. ${ }^{16}$ There is interest in identifying the physical aspects, including ECM composition and mechanical properties, that contribute to cellular activation and disease initiation and progression. Examples include barrier function and activation of endothelial and epithelial cells in response to stretch and shear, as well as fibroblast activation in response to stiffness and stretch of the ECM.

The biomechanical properties of lung tissue are strongly influenced by the biochemical composition of the ECM. The ECM in IPF is compositionally different from that in healthy lung tissue, with expanded collagens and glycosaminoglycans. ${ }^{17-19}$ Immunohistochemical analysis shows that fibroblastic foci are rich in collagen and EDAfibronectin. ${ }^{19}$ Periostin is a glycoprotein that is secreted by monocytes and fibrocytes, is overexpressed in IPF, and promotes fibrogenesis. ${ }^{20}$ The accumulation of additional ECM is due to enhanced myofibroblast activation and production of ECM, coupled with inhibited ECM turnover and degradation. ${ }^{21-23}$ Furthermore, posttranslational modification such as enzymatic and chemical cross-linking are altered in IPF and contribute to tissue stiffening. Increased mechanical forces within tissues activate latent transforming growth factor- $\beta$ (TGF- $\beta$ ) through integrin-dependent mechanisms, ${ }^{24-26}$ driving profibrotic effector functions, including ECM deposition and cross-linking that increase tissue stiffness and thereby further activates TGF- $\beta$ (Figure 1). Cross-linking enzymes include lysyl oxidase (LOX), lysyl oxidase-like (LOXL), and transglutaminases (TGs). Pathologic cross-linking due to up-regulation of LOXL and TG enzyme activity enhances fibroblast accumulation and increases resistance to ECM turnover. ${ }^{27}$ TG2 knockout mice are protected from bleomycin-induced pulmonary fibrosis. Serum LOXL2 levels are elevated in patients with IPF and are associated with increased risk of disease progression. ${ }^{28}$ Despite promising preclinical studies, ${ }^{29}$ a Phase II clinical trial with the LOXL2 inhibitor simtuzumab showed no effect on progression-free survival for patients with IPF. ${ }^{30}$ More in-depth details on the ECM of the lung in healthy and diseased states have been provided in several previously published review articles. ${ }^{16,31,32}$

Multiple mechanical forces contribute to pathologic tissue remodeling and fibrosis. Prior studies of lung tissue mechanics (in the normal and diseased states) have been limited to the characterization of matrix stiffness. ${ }^{11,17,26,33}$ Tissue stiffness, measured in kilopascals $(\mathrm{kPa})$, measures the force required for deformation. Normal lung tissue has a stiffness in the range of 0.5 to $5 \mathrm{kPa}$, whereas fibrotic lung tissue is in the range of 15 to $100 \mathrm{kPa} .^{11,17,26,33}$ Lung fibroblasts also experience mechanical forces from stretching, as the lungs expand and contract during breathing. Unlike either normal or fibrotic lung tissue, solid plastic tissue culture dishes have a substrate stiffness of approximately $100,000 \mathrm{kPa}$, and there is evidence that these forces induce nonphysiological cellular responses to mechanical strain. ${ }^{34-36}$

To better recapitulate the native physiological environment, researchers have developed in vitro model systems using silicone membranes or polyacrylamide gels with tunable substrate stiffness. ${ }^{37,38}$ There are now commercially available systems for tunable stiffness (Advanced BioMatrix, Carlsbad, $\mathrm{CA}$ ), as well as application of cyclic stretch (Flexcell International, Burlington, NC; Strex, San Diego, CA). Using custom and commercially available systems, investigators have begun to elucidate the effects of mechanical cues on fibroblast activation as well as mechanotransduction mechanisms. Increased stiffness both enhances recruitment of fibroblasts (durotaxis) ${ }^{39}$ and myofibroblast differentiation. ${ }^{11,25,32,40}$ Excitingly, reducing stiffness can 


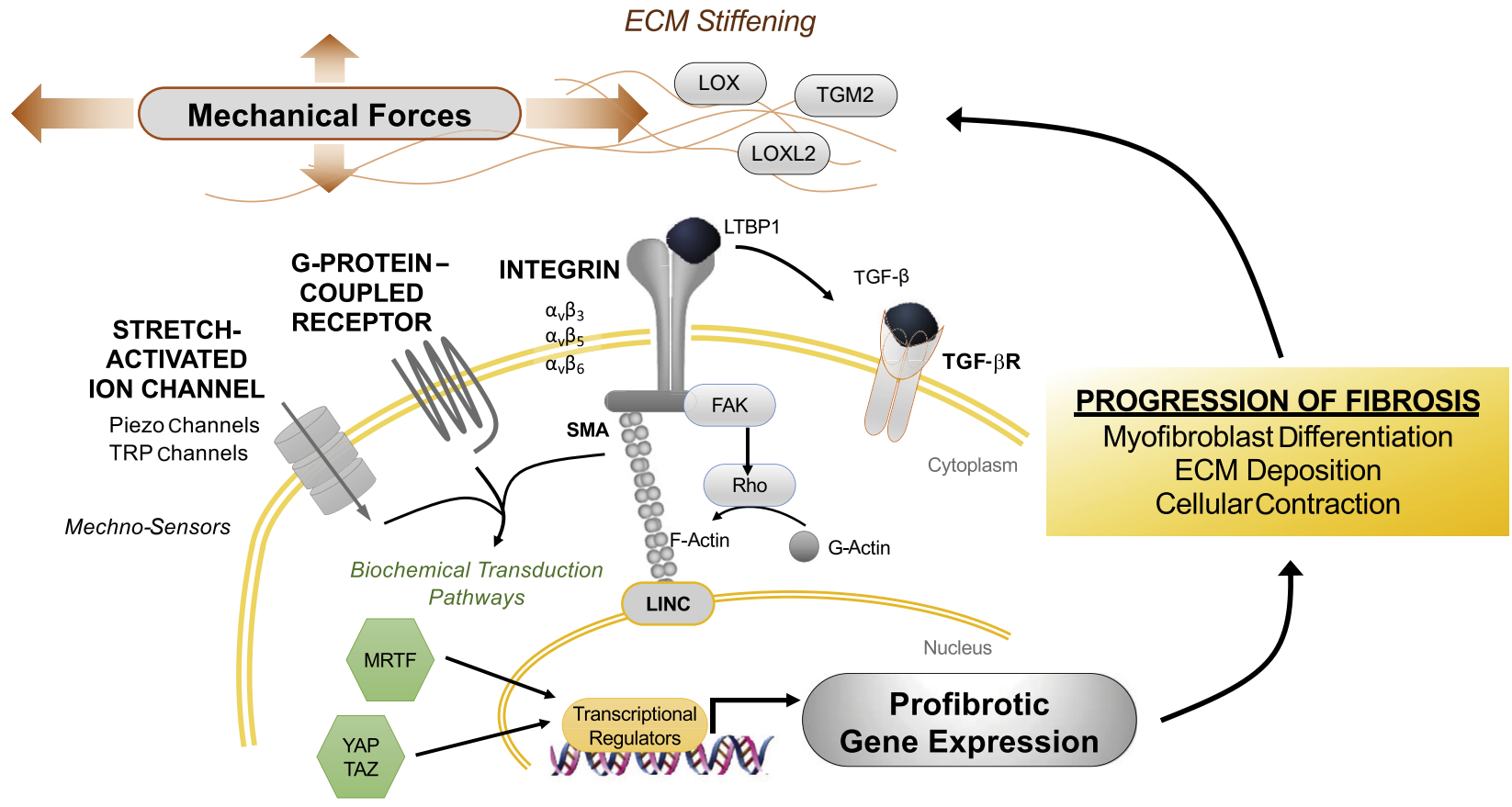

Figure 1 Mechanoreceptors and signal transduction pathways activating profibrotic gene expression. Fibroblasts sense mechanical cues such as cellular stretch and extracellular matrix stiffening through stretch-activated ion channels, G protein-coupled receptors, and integrins. RGD (arginine-glycineaspartate) integrin-linked focal adhesion complexes can activate Rho signaling leading to actin polymerization increasing $\alpha$-smooth muscle actin ( $\alpha$ SMA) and cellular contraction. Sensing of mechanical cues is followed by downstream activation of biochemical transduction pathways that converge on and regulate the nuclear translocation of myocardin-related transcription factor (MRTF) and Yes-associated protein (YAP)/transcriptional coactivator with PDZ-binding motif (TAZ). This leads to subsequent transcriptional regulation of profibrotic gene expression such as myofibroblast differentiation, extracellular matrix (ECM) deposition, and cellular contraction, further altering the mechanical microenvironment. In addition, application of externally applied force to the latencyassociated peptide and latent transforming growth factor $\beta$ (TGF- $\beta$ )-binding protein 1 (LTBP1) activates TGF- $\beta$ and canonical TGF- $\beta /$ SMAD signaling. FAK, focal adhesion kinase; LINC, linker of nucleoskeleton and cytoskeleton; TGF- $\beta$ R, TGF- $\beta$ receptor; TRP, transient receptor potential.

partially reverse a stiffness-induced myofibroblast phenotype. $^{36,41,42}$ This action supports the hypothesis that restoraton of healthy ECM will result in cells responding and reverting from their diseased phenotype to restore homeostasis. Lung tissue, as with other tissues in the body, has more complex mechanical properties, as they are viscoelastic, exhibiting stress-strain relationships dependent on time and history. This presents an opportunity to more comprehensively analyze the mechanical properties of lung tissue in healthy and diseased states, and then implement more complex in vitro systems to model the mechanical microenvironment.

IPF results in heterogeneous distribution of fibrotic lesions adjacent to normal-appearing areas within the lung. The boundary between the presumed healthy tissue and the fibrotic lesion introduces stress concentrations in which abrupt changes of mechanical properties are present, leading to high cellular and matrix strains at the transition. Furthermore, new techniques have revealed that the normal-appearing tissue adjacent to fibrotic lesions is not actually normal. Second harmonic generation imaging has shown that the fibrillar collagen microstructure of the "normal"-appearing tissue adjacent to fibrotic foci matches the second harmonic generation signature within the fibroblastic foci themselves. ${ }^{43} \mathrm{~A}$ similar phenomenon has been observed in liver fibrosis in which there is an observed increase in tissue stiffness before fibrotic matrix deposition. ${ }^{44}$ These data indicate that the ECM microstructure at the leading edge of a fibrotic lesion is altered before the alveolus is destroyed. The mechanical properties at the leading edge will be particularly important to characterize with extreme cellular mechanical forces experienced by it. There is a prime need to understand how lung cells, particularly fibroblasts, sense and respond to these mechanical signals to determine cellular responses within the transition region.

\section{Mechanotransduction}

\section{Mechanosensors}

The matrix is bioactive and communicates with cells. Cells sense changes in matrix mechanical properties through force-induced conformation change of mechanically sensitive molecules; this leads to the activation of downstream biochemical signaling pathways, a process defined as mechanotransduction. ${ }^{45,46}$ Mechanosensors reside on the cell membrane and include integrins, stretch-activated ion channels, and G protein coupled-receptors (Figure 1). 
Integrin-mediated mechanotransduction is the primary mechanism for cells to sense ECM mechanics. One critical mechanotransduction feed-forward loop in fibrosis is integrinmediated mechanical activation of latent TGF- $\beta^{47}$ (Figure 1). The integrins $\alpha_{\mathrm{v}} \beta_{3}, \alpha_{\mathrm{v}} \beta_{5}$, and $\alpha_{\mathrm{v}} \beta_{6}$ have been shown to bind the RGD sequence (arginine-glycine-aspartate) in the latencyassociated peptide of TGF- $\beta 1$ to activate latent TGF- $\beta{ }^{48-50}$ Integrins are up-regulated in fibrotic disease. ${ }^{48,51,52}$ In addition, stiffness-mediated ligation of the $\alpha_{\mathrm{V}} \beta_{3}$ integrin leads to myofibroblast activation. ${ }^{53}$ Ligation is also enhanced by low extracellular $\mathrm{pH}^{54}$ implicating potential cross-talk with another feed-forward fibrotic loop of dysregulated cellular metabolism in fibrosis. ${ }^{55,56}$ Recent studies have shown therapeutic efficacy in reducing kidney fibrosis with inhibition of RGD-binding integrins $\left(\alpha_{\mathrm{V}} \beta_{1}, \alpha_{\mathrm{V}} \beta_{3}\right.$, and $\left.\alpha_{\mathrm{V}} \beta_{6}\right)$ with CWHM$12 .^{57}$ A monoclonal antibody targeted against integrin $\alpha_{\mathrm{v}} \beta_{6}$ attenuated the development of bleomycin-induced fibrosis in mice. ${ }^{51}$ However, the clinical trial testing the monoclonal antibody BG0001 (formally STX-100) was terminated early because of safety concerns (https://www.clinicaltrials.gov; NCT01371035).

Mechanosensitive ion channels such as Piezo channels and the family of transient receptor potential (TRP) channels can also mediate the progression of fibrosis (Figure 1); however, the direct mechanisms are still being elucidated. TRP vanilloid 4 (TRPV4) is a nonselective cation channel, with high permeability to $\mathrm{Ca} 2+$, that opens in response to mechanical stresses. ${ }^{58-60}$ Inhibition of TRPV4 attenuated stiffness-induced cardio-myofibroblast differentiation. ${ }^{61}$ Furthermore, TRPV4 is essential for fibroblast to myofibroblast differentiation in vitro, and TRPV4 knockout mice are protected from bleomycin-induced pulmonary fibrosis, supporting its therapeutic potential. ${ }^{62}$ Piezo 1 and 2 are mechanically activated calcium ion channels. ${ }^{63-66}$ It is unclear whether Piezo channels play a role in fibrosis but are down-regulated in both small cell and non-small cell lung cancers. ${ }^{67}$ Loss of Piezo 1 and 2 promotes in vitro cell migration and in vivo tumor growth, ${ }^{68,69}$ but it remains unclear if it has implications in fibrosis.

\section{Transcription Factors}

Mechanical cues that are first sensed via receptors on the cell membrane are converted to chemical signals via mechanotransduction pathways that regulate many aspects of cell behavior, including motility, proliferation, morphology, and survival. Downstream signaling following activation of the mechanosensors discussed earlier often converges on several common transcription factors.

Yes-associated protein (YAP) is a transcriptional coactivator of the hippo signaling pathway. There are multiple upstream signals that regulate the hippo pathway, including $\mathrm{G}$ protein-coupled receptor signaling, ${ }^{70}$ Wnt signaling, ${ }^{71}$ and mechanical stress. ${ }^{72}$ YAP interacts with its paralog transcriptional coactivator with PDZ-binding motif (TAZ). Both YAP and TAZ increase expression in response to substrates of higher stiffness. ${ }^{72,73}$ YAP and TAZ are expressed in fibrotic but not healthy lung tissue. ${ }^{73,74}$ Furthermore, the profibrotic effects of YAP/TAZ can in part be attributed to activating plasminogen activator inhibitor- 1 , independent of TGF- $\beta$ signaling. ${ }^{73}$ Plasminogen activator inhibitor-1 contributes to fibrosis by suppressing matrix remodeling ${ }^{73,75-77}$ and altered cell cycle pathways through mammalian target of rapamycin/ phosphatidylinositol 3-kinase. ${ }^{78,79}$ This creates another mechanotransduction feed-forward loop increasing matrix stiffness, hippo-YAP/TAZ signaling, myofibroblast activation, and fibrosis progression with increasing tissue stiffness (Figure 1). In addition, up-regulation in TAZ has been shown to promote the epithelial-mesenchymal transition, a process that contributes to an expanded myofibroblast population in tissues in fibrotic pathologies. ${ }^{80}$ Excitingly, pharmacologic inhibition of YAP/TAZ with $\mathrm{G} \alpha_{\mathrm{s}}$-coupled dopamine receptor D1 reverses bleomycin-induced fibrosis in mice when administered starting 10 days after bleomycin injury. ${ }^{81}$ Systemic YAP/TAZ inhibition with the receptor agonist ACT333679 also illustrates the antifibrotic effects in vitro. ${ }^{82}$

The myocardin-related transcription factors (MRTFs) A and $\mathrm{B}$ act as cofactors for serum response factor; they are mechanosensitive transcription factors that regulate genes encoding structural and regulatory effectors of actin dynamics. The biomechanical cellular environment regulates MRTF nuclear translocation because MRTF binds to Gactin. Investigation of human lung fibroblasts grown on polyacrylamide gels of physiologically healthy and fibrotic stiffness showed that MRTF-A is required for stiffnessinduced myofibroblast differentiation. ${ }^{13}$ Furthermore, inhibition of MRTF-A signaling ameliorates bleomycin-induced fibrosis in mice. ${ }^{83,84}$ In addition, inhibition of MRTF signaling with CCG-203971 enhances fibroblast apoptosis in experimental models of fibrosis. ${ }^{85}$ Deletion of MRTF-A also reduced fibrosis after myocardial infarction, ${ }^{86}$ indicating potential overlapping mechanisms across multiple organ fibroses. However, MRTF-A/B and YAP/TAZ crosstalk with SMAD3 downstream of TGF- $\beta,{ }^{87-89}$ indicating a number of redundant and confounding profibrotic pathways.

\section{Therapeutic Implications}

Targeting of the matrix and mechanotransduction pathways has emerged as a potential therapeutic approach for IPF. Cessation of the progressive stiffening of the ECM is likely to be a key component of halting the overall progression of disease. Previous clinical studies have investigated inhibiting the progressive stiffening caused by matrix cross-linking activity (LOXL2) (https://www.clinicaltrials.gov; NCT01769196) and mechanosensing by integrins (https://www.clinicaltrials.gov; NCT03573505). RAINIER [Study to Assess the Efficacy and Safety of Simtuzumab (GS-6624) in Adults with Idiopathic Pulmonary Fibrosis (IPF); https://www.clinicaltrials.gov; NCT01769196] was a Phase II randomized controlled trial investigating the potential role of simtuzumab, an antibody 
targeting LOXL2, in patients with $\mathrm{IPF}^{30}$ Although the medication was safe, it failed to reach the primary or secondary outcomes, including mortality, disease-free progression, forced vital capacity (percent) decline, and 6minute walk distance. It is not clear why this trial did not achieve the primary outcome. It is possible that the inhibitor was effective at reducing matrix cross-linking, but that it was insufficient to inhibit further myofibroblast differentiation and proliferation. Another possibility is that other matrix cross-linking enzymes may have compensated for the decreased LOXL2 activity to maintain a stable level of collagen cross-linking.

Despite the success of preclinical animal studies, ${ }^{51}$ the SPIRIT trial (An Efficacy and Safety Study of BG00011 in Participants With Idiopathic Pulmonary Fibrosis; https:// www.clinicaltrials.gov; NCT03573505) investigating the role of a monoclonal antibody against integrin $\alpha \nu b 6$ was terminated early because of safety concerns. ${ }^{90}$ However, there are several promising therapies currently in phase 2 clinical trials. $^{91}$

There is mounting evidence that fibrosis is perpetuated by multiple overlapping feed-forward loops, ${ }^{92}$ of which mechanical stiffness is only one. Due to this redundancy, it may be unrealistic that a "magic bullet" on a sole target will have the ability to halt IPF progression. We envision that the future of IPF therapy will incorporate a fibroblast blocker (eg, nintedanib, pirfenidone) in combination with blockades of multiple accessory pathways such as matrix cross-linking (TG2, LOXlike enzymes), matrix sensing, Wnt signaling, ${ }^{93}$ metabolism, ${ }^{56,94}$ and others to halt fibrosis by acting on major and accessory pathways involved in the disease. In this context, matrix stiffening may be one of the important targets, with other therapeutics focusing on growth factors, myofibroblasts, or damaged epithelium. Preventing lung fibroblasts from sensing the stiffness of their environment and responding to it by using sensor or transcription factor inhibitors might have more potential than blocking cross-linking enzymes, as that would reduce the profibrotic activities of fibroblasts in established fibrotic lesions as well as at the fibrotic front (fibrosis/ normal interface). For example, targeting the sensing of altered mechanics (eg, integrins, TRP channels, Piezo channels) or the transcription factors that direct gene expression in response to stiffness (eg, YAP/TAZ, MRTF) is expected to down-regulate multiple important pathways, including matrix production and cross-linking by TG2, LOX, and LOXLs (Figure 1).

Direct inhibition of cross-linking enzymes is not expected to reverse excess cross-links in established fibrotic areas. However, targeting mechanotransduction sensors and transcription factors has the benefit of blocking profibrotic stiffness signals, even in fibroblasts located in established fibrotic zones, and may allow the cell to return to a more homeostatic state. In addition, it may be worth re-evaluating candidates (eg, simtuzumab, integrin blocking) that reported efficacy in preclinical animal models but were not successful as monotherapies in human trials in new combinations with pirfenidone or nintedanib to see if they would be effective in combination and possibly at lower doses that would present fewer safety issues.

Overall, complex pathologic conditions such as fibrosis will likely require multipronged therapeutic approaches targeting several pathways, similar to the way we treat many cancers. Current US Food and Drug Administration-approved therapies exhibit some efficacy in slowing the progression of fibrosis. However, the involvement of multiple pathways potentially requires targeting of these independent mechanisms to achieve the goal of halting disease progression. Interestingly, both therapies for IPF (pirfenidone and nintedanib) currently approved by the US Food and Drug Administration have multifactorial modes of action that are still being investigated. The potential of combining antifibrotic therapies has already been explored both in vitro ${ }^{95}$ and in vivo in the INJOURNEY (Safety, Tolerability and PK of Nintedanib in Combination With Pirfenidone in IPF) trial. ${ }^{96}$

\section{Future Directions}

There are several gaps in knowledge that, when filled, will advance our understanding of the role of matrix mechanics and mechanotransduction pathways in the progression of pulmonary fibrosis. One step will be to test the therapeutic benefit of inhibiting identified mechanics altering pathways, mechanosensors, and transcription factors in preclinical models of pulmonary fibrosis, discussed earlier in Therapeutic Implications. The overarching goal of targeting mechanotransduction mechanisms is to block the profibrotic mechanical signal and halt further progression of fibrosis, likely when combined with other options (eg, pirfenidone or nintedanib) currently approved by the US Food and Drug Administration. Researchers have yet to explore the potential synergistic effects of combining approved therapies with targeting mechanotransduction or mechanical changes. Moreover, identifying ways to selectively interfere with the fibrotic process in the lung, by either focusing on targets specific for the respiratory system or by using medication vehicles that ensure a localized delivery (ie, inhaled aerosols) may increase the safety of these interventions by limiting the systemic side effects. Another objective will be to further elucidate mechanotransduction pathways, not only in fibroblasts but also in epithelial cells. To date, the mechanical characterization of lung tissue has primarily been limited to the assessment of matrix stiffness. However, more complex mechanical properties alter cell behavior. To better understand the role of altered matrix mechanics, we need comprehensive mechanical characterization of all compartments of the lung, including viscoelastic properties of healthy and diseased lung. Following the identification of altered mechanical properties, there will be a need to systemically characterize how altered mechanics in disease progression drives cellular response of not just fibroblasts but all predominant cell types within the lung. 


\section{Conclusions}

The importance of biomechanical signaling in disease pathogenesis is now accepted as a critical driver of disease progression. Increased tissue stiffness within the fibrotic foci is sensed and translated into profibrotic gene expression that further increases stiffness. Recent studies reviewed here help elucidate the role of mechanotransduction in the progression of IPF. It remains uncertain if and how mechanotransduction plays a role in the initiation of the disease. Targeting mechanotransduction pathways to treat IPF has the potential, when combined with other therapeutic interventions, to halt the progression of fibrosis. However, much work is still needed to elucidate pathologic mechanisms of applied mechanical forces independent of and in conjunction with the altered biochemical composition of the ECM. Beyond halting the expansion of the fibrotic matrix, long-term goals aim to degrade and regenerate the native lung environment to restore homeostatic cell-cell and cell-matrix interactions. Collectively, these advances in understanding mechanotransduction feed-forward loops in fibrosis have the potential to provide opportunities for identifying novel therapeutic targets for combination therapies to halt the progression of IPF.

\section{References}

1. Baroke E, Gauldie J, Kolb M: New treatment and markers of prognosis for idiopathic pulmonary fibrosis: lessons learned from translational research. Expert Rev Respir Med 2013, 7:465-478

2. Nathan SD, Shlobin OA, Weir N, Ahmad S, Kaldjob JM, Battle E, Sheridan MJ, du Bois RM: Long-term course and prognosis of idiopathic pulmonary fibrosis in the new millennium. Chest 2011, 140:221-229

3. Schwartz DA, Helmers RA, Galvin JR, Van Fossen DS, Frees KL, Dayton CS, Burmeister LF, Hunninghake GW: Determinants of survival in idiopathic pulmonary fibrosis. Am J Respir Crit Care Med 1994, 149(Pt 1):450-454

4. Wolff J: Das Gesetz der Transformation der Knochen. Berlin, Verlag von August Hirschwald, 1892

5. Fuchs RK, Warden SJ, Turner CH: Bone anatomy, physiology and adaptation to mechanical loading. Edited by Bone Repair Biomaterials. New York, NY: Elsevier Inc., 2009. pp. 25-68

6. Roan E, Waters CM: What do we know about mechanical strain in lung alveoli? Am J Physiol Lung Cell Mol Physiol 2011, 301: L625-L635

7. Sicard D, Haak AJ, Choi KM, Craig AR, Fredenburgh LE, Tschumperlin DJ: Aging and anatomical variations in lung tissue stiffness. Am J Physiol Lung Cell Mol Physiol 2018, 314: L946-L955

8. Suki B, Stamenović D, Hubmayr R: Lung parenchymal mechanics. Compr Physiol 2011, 1:1317-1351

9. Knudsen L, Ochs M: The micromechanics of lung alveoli: structure and function of surfactant and tissue components. Histochem Cell Biol 2018, 150:661-676

10. Herum KM, Choppe J, Kumar A, Engler AJ, McCulloch AD: Mechanical regulation of cardiac fibroblast profibrotic phenotypes. Mol Biol Cell 2017, 28:1871-1882

11. Liu F, Mih JD, Shea BS, Kho AT, Sharif AS, Tager AM, Tschumperlin DJ: Feedback amplification of fibrosis through matrix stiffening and COX-2 suppression. J Cell Biol 2010, 190:693-706
12. Santos A, Lagares D: Matrix stiffness: the conductor of organ fibrosis. Curr Rheumatol Rep 2018, 20:2

13. Huang X, Yang N, Fiore VF, Barker TH, Sun Y, Morris SW, Ding Q, Thannickal VJ, Zhou Y: Matrix stiffness-induced myofibroblast differentiation is mediated by intrinsic mechanotransduction. Am J Respir Cell Mol Biol 2012, 47:340-348

14. Tschumperlin DJ, Ligresti G, Hilscher MB, Shah VH: Mechanosensing and fibrosis. J Clin Invest 2018, 128:74-84

15. Maher TM, Strek ME: Antifibrotic therapy for idiopathic pulmonary fibrosis: time to treat. Respir Res 2019, 20:205

16. Burgstaller G, Oehrle B, Gerckens M, White ES, Schiller HB, Eickelberg O: The instructive extracellular matrix of the lung: basic composition and alterations in chronic lung disease. Eur Respir J 2017, 50:1601805

17. Booth AJ, Hadley R, Cornett AM, Dreffs AA, Matthes SA, Tsui JL, Weiss K, Horowitz JC, Fiore VF, Barker TH, Moore BB, Martinez FI, Niklason LE, White ES: Acellular normal and fibrotic human lung matrices as a culture system for in vitro investigation. Am J Respir Crit Care Med 2012, 186:866-876

18. Raghu G, Striker LJ, Hudson LD, Striker GE: Extracellular matrix in normal and fibrotic human lungs. Am Rev Respir Dis 1985, 131: 281-289

19. Kuhn C 3rd, Boldt J, King TE, Crouch E, Vartio T, McDonald JA: An immunohistochemical study of architectural remodeling and connective tissue synthesis in pulmonary fibrosis. Am Rev Respir Dis 1989, 140:1693-1703

20. Naik PK, Bozyk PD, Bentley JK, Popova AP, Birch CM, Wilke CA, Fry CD, White ES, Sisson TH, Tayob N, Carnemolla B, Orecchia P, Flaherty KR, Hershenson MB, Murray S, Martinez FJ, Moore BB; COMET Investigators: Periostin promotes fibrosis and predicts progression in patients with idiopathic pulmonary fibrosis. Am J Physiol Lung Cell Mol Physiol 2012, 303:L1046-L1056

21. Kadler KE, Hill A, Canty-Laird EG: Collagen fibrillogenesis: fibronectin, integrins, and minor collagens as organizers and nucleators. Curr Opin Cell Biol 2008, 20:495-501

22. Branton MH, Kopp JB: TGF- $\beta$ and fibrosis. Microbes Infect 1999, 1 : $1349-1365$

23. Chanda D, Otoupalova E, Smith SR, Volckaert T, De Langhe SP, Thannickal VJ: Developmental pathways in the pathogenesis of lung fibrosis. Mol Aspects Med 2019, 65:56-69

24. Buscemi L, Ramonet D, Klingberg F, Formey A, Smith-Clerc J, Meister JJ, Hinz B: The single-molecule mechanics of the latent TGF[beta]1 complex. Curr Biol 2011, 21:2046-2054

25. Hinz B: Tissue stiffness, latent TGF-beta1 activation, and mechanical signal transduction: implications for the pathogenesis and treatment of fibrosis. Curr Rheumatol Rep 2009, 11:120-126

26. Hinz B, Phan SH, Thannickal VJ, Prunotto M, Desmoulière A, Varga J, De Wever O, Mareel M, Gabbiani G: Recent developments in myofibroblast biology: paradigms for connective tissue remodeling. Am J Pathol 2012, 180:1340-1355

27. Philp CJ, Siebeke I, Clements D, Miller S, Habgood A, John AE, Navaratnam V, Hubbard RB, Jenkins G, Johnson SR: Extracellular matrix cross-linking enhances fibroblast growth and protects against matrix proteolysis in lung fibrosis. Am J Respir Cell Mol Biol 2018, 58:594-603

28. Chien JW, Richards TJ, Gibson KF, Zhang Y, Lindell KO, Shao L, Lyman SK, Adamkewicz JI, Smith V, Kaminski N, O'Riordan T: Serum lysyl oxidase-like 2 levels and idiopathic pulmonary fibrosis disease progression. Eur Respir J 2014, 43:1430-1438

29. Roberts J, Tear V, Lunn K, Cao L, Murphy J, Shimbori C, Imani J, Tandon K, Ayaub E, Jones M, Davies D, Jarolimek W, Ask K, Gauldie J, Kolb M, Monk P: Evaluation of novel LOXL2-selective inhibitors in models of pulmonary fibrosis. Eur Respir J 2017, 50: PA3476

30. Raghu G, Brown KK, Collard HR, Cottin V, Gibson KF, Kaner RJ, Lederer DJ, Martinez FJ, Noble PW, Song JW, Wells AU, Whelan TPM, Wuyts W, Moreau E, Patterson SD, Smith V, Bayly S, 
Chien JW, Gong Q, Zhang JJ, O'Riordan TG: Efficacy of simtuzumab versus placebo in patients with idiopathic pulmonary fibrosis: a randomised, double-blind, controlled, phase 2 trial. Lancet Respir Med 2017, 5:22-32

31. Thannickal VJ, Henke CA, Horowitz JC, Noble PW, Roman J, Sime PJ, Zhou Y, Wells RG, White ES, Tschumperlin DJ: Matrix biology of idiopathic pulmonary fibrosis: a workshop report of the National Heart, Lung, and Blood Institute. Am J Pathol 2014, 184: $1643-1651$

32. Upagupta C, Shimbori C, Alsilmi R, Kolb M: Matrix abnormalities in pulmonary fibrosis. Eur Respir Rev 2018, 27:180033

33. Southern BD, Grove LM, Rahaman SO, Abraham S, Scheraga RG, Niese KA, Sun H, Herzog EL, Liu F, Tschumperlin DJ, Egelhoff TT, Rosenfeld SS, Olman MA: Matrix-driven myosin II mediates the pro-fibrotic fibroblast phenotype. J Biol Chem 2016, 291:6083-6095

34. Solon J, Levental I, Sengupta K, Georges PC, Janmey PA: Fibroblast adaptation and stiffness matching to soft elastic substrates. Biophys J 2007, 93:4453-4461

35. Achterberg VF, Buscemi L, Diekmann H, Smith-Clerc J, Schwengler H, Meister JJ, Wenck H, Gallinat S, Hinz B: The nano-scale mechanical properties of the extracellular matrix regulate dermal fibroblast function. J Invest Dermatol 2014, 134: $1862-1872$

36. Caliari SR, Perepelyuk M, Cosgrove BD, Tsai SJ, Lee GY, Mauck RL, Wells RG, Burdick JA: Stiffening hydrogels for investigating the dynamics of hepatic stellate cell mechanotransduction during myofibroblast activation. Sci Rep 2016, 6:21387

37. Syed S, Karadaghy A, Zustiak S: Simple polyacrylamide-based multiwell stiffness assay for the study of stiffness-dependent cell responses. J Vis Exp 2015, 25:52643

38. Tse JR, Engler AJ: Preparation of hydrogel substrates with tunable mechanical properties. Curr Protoc Cell Biol 2010. Chapter 10:16

39. Lo CM, Wang HB, Dembo M, Wang YL: Cell movement is guided by the rigidity of the substrate. Biophys J 2000, 79:144-152

40. Balestrini JL, Chaudhry S, Sarrazy V, Koehler A, Hinz B: The mechanical memory of lung myofibroblasts. Integr Biol (Camb) 2012, 4 410-421

41. Caliari SR, Perepelyuk M, Soulas EM, Lee GY, Wells RG, Burdick JA: Gradually softening hydrogels for modeling hepatic stellate cell behavior during fibrosis regression. Integr Biol (Camb) 2016, 8:720-728

42. Marinković A, Liu F, Tschumperlin DJ: Matrices of physiologic stiffness potently inactivate idiopathic pulmonary fibrosis fibroblasts. Am J Respir Cell Mol Biol 2013, 48:422-430

43. Kottmann RM, Sharp J, Owens K, Salzman P, Xiao GQ, Phipps RP, Sime PJ, Brown EB, Perry SW: Second harmonic generation microscopy reveals altered collagen microstructure in usual interstitial pneumonia versus healthy lung. Respir Res 2015, 16:61

44. Georges PC, Hui JJ, Gombos Z, McCormick ME, Wang AY, Uemura M, Mick R, Janmey PA, Furth EE, Wells RG: Increased stiffness of the rat liver precedes matrix deposition: implications for fibrosis. Am J Physiol Gastrointest Liver Physiol 2007, 293: G1147-G1154

45. Balaban NQ, Schwarz US, Riveline D, Goichberg P, Tzur G, Sabanay I, Mahalu D, Safran S, Bershadsky A, Addadi L, Geiger B: Force and focal adhesion assembly: a close relationship studied using elastic micropatterned substrates. Nat Cell Biol 2001, 3:466-472

46. Sun Z, Guo SS, Fässler R: Integrin-mediated mechanotransduction. J Cell Biol 2016, 215:445-456

47. Henderson NC, Sheppard D: Integrin-mediated regulation of TGF [beta] in fibrosis. Biochim Biophys Acta 2013, 1832:891-896

48. Munger JS, Huang X, Kawakatsu H, Griffiths MJ, Dalton SL, Wu J, Pittet JF, Kaminski N, Garat C, Matthay MA, Rifkin DB, Sheppard D: The integrin alpha $\mathrm{v}$ beta 6 binds and activates latent TGF beta 1: a mechanism for regulating pulmonary inflammation and fibrosis. Cell 1999, 96:319-328
49. Asano Y, Ihn H, Yamane K, Jinnin M, Tamaki K: Increased expression of integrin alphavbeta5 induces the myofibroblastic differentiation of dermal fibroblasts. Am J Pathol 2006, 168:499-510

50. Wipff PJ, Rifkin DB, Meister JJ, Hinz B: Myofibroblast contraction activates latent TGF-betal from the extracellular matrix. J Cell Biol 2007, 179:1311-1323

51. Horan GS, Wood S, Ona V, Dan JL, Lukashev ME, Weinreb PH, Simon KJ, Hahm K, Allaire NE, Rinaldi NJ, Goyal J, FeghaliBostwick CA, Matteson EL, O'Hara C, Lafyatis R, Davis GS, Huang X, Sheppard D, Violette SM: Partial inhibition of integrin alpha(v)beta6 prevents pulmonary fibrosis without exacerbating inflammation. Am J Respir Crit Care Med 2008, 177:56-65

52. Asano $\mathrm{Y}$, Ihn $\mathrm{H}$, Yamane $\mathrm{K}$, Jinnin M, Mimura Y, Tamaki $\mathrm{K}$ : Increased expression of integrin alpha(v)beta 3 contributes to the establishment of autocrine TGF-beta signaling in scleroderma fibroblasts. J Immunol 2005, 175:7708-7718

53. Knipe RS, Tager AM, Liao JK: The Rho kinases: critical mediators of multiple profibrotic processes and rational targets for new therapies for pulmonary fibrosis. Pharmacol Rev 2015, 67:103-117

54. Paradise RK, Lauffenburger DA, Van Vliet KJ: Acidic extracellular $\mathrm{pH}$ promotes activation of integrin [alpha](v)[beta](3). PLoS One 2011, 6:e15746

55. Kottmann RM, Trawick E, Judge JL, Wahl LA, Epa AP, Owens KM, Thatcher TH, Phipps RP, Sime PJ: Pharmacologic inhibition of lactate production prevents myofibroblast differentiation. Am J Physiol Cell Mol Physiol 2015, 309:L1305-L1312

56. Kottmann RM, Kulkarni AA, Smolnycki KA, Lyda E, Dahanayake T, Salibi R, Honnons S, Jones C, Isern NG, Hu JZ, Nathan SD, Grant G, Phipps RP, Sime PJ: Lactic acid is elevated in idiopathic pulmonary fibrosis and induces myofibroblast differentiation via $\mathrm{pH}$-dependent activation of transforming growth factor-[beta]. Am J Respir Crit Care Med 2012, 186:740-751

57. Basta J, Robbins L, Stout L, Prinsen MJ, Griggs DW, Rauchman M: Pharmacologic inhibition of RGD-binding integrins ameliorates fibrosis and improves function following kidney injury. Physiol Rep 2020, 8:e14329

58. Zhan L, Li J: The role of TRPV4 in fibrosis. Gene 2018, 642:1-8

59. Inoue R, Jian Z, Kawarabayashi Y: Mechanosensitive TRP channels in cardiovascular pathophysiology. Pharmacol Ther 2009, 123: 371-385

60. Scheraga RG, Abraham S, Niese KA, Southern BD, Grove LM, Hite RD, McDonald C, Hamilton TA, Olman MA: TRPV4 mechanosensitive ion channel regulates lipopolysaccharide-stimulated macrophage phagocytosis. J Immunol 2016, 196:428-436

61. Adapala RK, Thoppil RJ, Luther DJ, Paruchuri S, Meszaros JG Chilian WM, Thodeti CK: TRPV4 channels mediate cardiac fibroblast differentiation by integrating mechanical and soluble signals. J Mol Cell Cardiol 2013, 54:45-52

62. Rahaman SO, Grove LM, Paruchuri S, Southern BD, Abraham S, Niese KA, Scheraga RG, Ghosh S, Thodeti CK, Zhang DX, Moran MM, Schilling WP, Tschumperlin DJ, Olman MA: TRPV4 mediates myofibroblast differentiation and pulmonary fibrosis in mice. J Clin Invest 2014, 124:5225-5238

63. He L, Si G, Huang J, Samuel ADT, Perrimon N: Mechanical regulation of stem-cell differentiation by the stretch-activated Piezo channel. Nature 2018, 555:103-106

64. Blythe NM, Muraki K, Ludlow MJ, Stylianidis V, Gilbert HTJ, Evans EL, Cuthbertson K, Foster R, Swift J, Li J, Drinkhill MJ, van Nieuwenhoven FA, Porter KE, Beech DJ, Turner NA: Mechanically activated Piezo1 channels of cardiac fibroblasts stimulate p38 mitogen-activated protein kinase activity and interleukin-6 secretion. J Biol Chem 2019, 294:17395-17408

65. Zhong M, Komarova Y, Rehman J, Malik AB: Mechanosensing piezo channels in tissue homeostasis including their role in lungs. Pulm Circ 2018, 8. 2045894018767393

66. Coste B, Xiao B, Santos JS, Syeda R, Grandl J, Spencer KS, Kim SE, Schmidt M, Mathur J, Dubin AE, Montal M, Patapoutian A: Piezo 
proteins are pore-forming subunits of mechanically activated channels. Nature 2012, 483:176-181

67. Györffy B, Surowiak P, Budczies J, Lánczky A: Online survival analysis software to assess the prognostic value of biomarkers using transcriptomic data in non-small-cell lung cancer. PLoS One 2013, 8: e82241

68. Huang Z, Sun Z, Zhang X, Niu K, Wang Y, Zheng J, Li H, Liu Y: Loss of stretch-activated channels, PIEZOs, accelerates non-small cell lung cancer progression and cell migration. Biosci Rep 2019, 39. BSR20181679

69. Chubinskiy-Nadezhdin VI, Vasileva VY, Vassilieva IO, Sudarikova AV, Morachevskaya EA, Negulyaev YA: Agonistinduced Piezol activation suppresses migration of transformed fibroblasts. Biochem Biophys Res Commun 2019, 514:173-179

70. Yu FX, Zhao B, Panupinthu N, Jewell JL, Lian I, Wang LH, Zhao J, Yuan H, Tumaneng K, Li H, Fu XD, Mills GB, Guan KL: Regulation of the Hippo-YAP pathway by G-protein-coupled receptor signaling. Cell 2012, 150:780-791

71. Konsavage WM Jr, Yochum GS: Intersection of Hippo/YAP and Wnt/[beta]-catenin signaling pathways. Acta Biochim Biophys Sin 2013, 45:71-79

72. Dupont S, Morsut L, Aragona M, Enzo E, Giulitti S, Cordenonsi M, Zanconato F, Le Digabel J, Forcato M, Bicciato S, Elvassore N, Piccolo S: Role of YAP/TAZ in mechanotransduction. Nature 2011, 474:179-183

73. Liu F, Lagares D, Choi KM, Stopfer L, Marinković A, Vrbanac V, Probst CK, Hiemer SE, Sisson TH, Horowitz JC, Rosas IO, Fredenburgh LE, Feghali-Bostwick C, Varelas X, Tager AM, Tschumperlin DJ: Mechanosignaling through YAP and TAZ drives fibroblast activation and fibrosis. Am J Physiol Cell Mol Physiol 2015, 308:L344-L357

74. Noguchi S, Saito A, Mikami Y, Urushiyama H, Horie M, Matsuzaki H, Takeshima H, Makita K, Miyashita N, Mitani A, Jo T, Yamauchi Y, Terasaki Y, Nagase T: TAZ contributes to pulmonary fibrosis by activating profibrotic functions of lung fibroblasts. Sci Rep 2017, 7:42595

75. Ghosh AK, Vaughan DE: PAI-1 in tissue fibrosis. J Cell Physiol 2012, 227:493-507

76. Flevaris $\mathrm{P}$, Vaughan D: The role of plasminogen activator inhibitor type-1 in fibrosis. Semin Thromb Hemost 2017, 43:169-177

77. Freeberg MAT, Farhat YM, Easa A, Kallenbach JG, Malcolm DW, Buckley MR, Benoit DSW, Awad HA: Serpine1 knockdown enhances MMP activity after flexor tendon injury in mice: implications for adhesions therapy. Sci Rep 2018, 8:5810

78. Freeberg MAT, Easa A, Lillis JA, Benoit DSW, van Wijnen AJ, Awad HA: Transcriptomic analysis of cellular pathways in healing flexor tendons of plasminogen activator inhibitor 1 (PAI-1/Serpine1) null mice. J Orthop Res 2020, 38:43-58

79. Samarakoon R, Helo S, Dobberfuhl AD, Khakoo NS, Falke L, Overstreet JM, Goldschmeding R, Higgins PJ: Loss of tumour suppressor PTEN expression in renal injury initiates SMAD3and p53-dependent fibrotic responses. J Pathol 2015, 236: 421-432

80. Lei QY, Zhang H, Zhao B, Zha ZY, Bai F, Pei XH, Zhao S, Xiong Y, Guan KL: TAZ promotes cell proliferation and epithelialmesenchymal transition and is inhibited by the hippo pathway. Mol Cell Biol 2008, 28:2426-2436

81. Haak AJ, Kostallari E, Sicard D, Ligresti G, Choi KM, Caporarello N, Jones DL, Tan Q, Meridew J, Diaz Espinosa AM, Aravamudhan A, Maiers JL, Britt RD Jr, Roden AC, Pabelick CM, Prakash YS, Nouraie SM, Li X, Zhang Y, Kass DJ, Lagares D, Tager AM, Varelas X, Shah VH, Tschumperlin DJ: Selective YAP/TAZ inhibition in fibroblasts via dopamine receptor D1 agonism reverses fibrosis. Sci Transl Med 2019, 11:eaau6296
82. Zmajkovicova K, Menyhart K, Bauer Y, Studer R, Renault B, Schnoebelen M, Bolinger M, Nayler O, Gatfield J: The antifibrotic activity of prostacyclin receptor agonism is mediated through inhibition of YAP/TAZ. Am J Respir Cell Mol Biol 2019, 60:578-591

83. Zhou Y, Huang X, Hecker L, Kurundkar D, Kurundkar A, Liu H, Jin TH, Desai L, Bernard K, Thannickal VJ: Inhibition of mechanosensitive signaling in myofibroblasts ameliorates experimental pulmonary fibrosis. J Clin Invest 2013, 123:1096-1108

84. Haak AJ, Tsou PS, Amin MA, Ruth JH, Campbell P, Fox DA, Khanna D, Larsen SD, Neubig RR: Targeting the myofibroblast genetic switch: inhibitors of myocardin-related transcription factor/serum response factor-regulated gene transcription prevent fibrosis in a murine model of skin injury. J Pharmacol Exp Ther 2014, 349: 480-486

85. Sisson TH, Ajayi IO, Subbotina N, Dodi AE, Rodansky ES, Chibucos LN, Kim KK, Keshamouni VG, White ES, Zhou Y, Higgins PD, Larsen SD, Neubig RR, Horowitz JC: Inhibition of myocardin-related transcription factor/serum response factor signaling decreases lung fibrosis and promotes mesenchymal cell apoptosis. Am J Pathol 2015, 185:969-986

86. Small EM, Thatcher JE, Sutherland LB, Kinoshita H, Gerard RD, Richardson JA, Dimaio JM, Sadek H, Kuwahara K, Olson EN: Myocardin-related transcription factor-a controls myofibroblast activation and fibrosis in response to myocardial infarction. Circ Res 2010, 107:294-304

87. Speight P, Kofler M, Szászi K, Kapus A: Context-dependent switch in chemo/mechanotransduction via multilevel crosstalk among cytoskeleton-regulated MRTF and TAZ and TGF[beta]-regulated Smad3. Nat Commun 2016, 7:11642

88. Miranda MZ, Bialik JF, Speight P, Dan Q, Yeung T, Szászi K, Pedersen SF, Kapus A: TGF-[beta]1 regulates the expression and transcriptional activity of TAZ protein via a Smad3-independent, myocardin-related transcription factor-mediated mechanism. J Biol Chem 2017, 292:14902-14920

89. Tschumperlin DJ, Liu F, Tager AM: Biomechanical regulation of mesenchymal cell function. Curr Opin Rheumatol 2013, 25:92-100

90. Arefayene M, Mouded M, Stebbins C, Zhao G, Song G, Christmann R, Violette S, Gallagher D: Phase 2B dose selection of BG00011 for the treatment of idiopathic pulmonary fibrosis (IPF). Eur Respir J 2018, 52:PA596

91. Saito S, Alkhatib A, Kolls JK, Kondoh Y, Lasky JA: Pharmacotherapy and adjunctive treatment for idiopathic pulmonary fibrosis (IPF). J Thorac Dis 2019, 11 Suppl:S1740-S1754

92. Rackow A, Nagel DJ, McCarthy C, Judge J, Lacy S, Freeberg MAT, Thatcher TH, Kottmann RM, Sime PJ: The self-fulfilling prophecy of pulmonary fibrosis: a selective inspection of pathologic signaling loops. Eur Respir J 2020, 56:2000075

93. Jeon KI, Phipps RP, Sime PJ, Huxlin KR: Antifibrotic actions of peroxisome proliferator-activated receptor [gamma] ligands in corneal fibroblasts are mediated by [beta]-catenin-regulated pathways. Am J Pathol 2017, 187:1660-1669

94. Judge JL, Nagel DJ, Owens KM, Rackow A, Phipps RP, Sime PJ, Kottmann RM: Prevention and treatment of bleomycin-induced pulmonary fibrosis with the lactate dehydrogenase inhibitor gossypol. PLoS One 2018, 13:e0197936

95. Vu TN, Chen X, Foda HD, Smaldone GC, Hasaneen NA: Interferon[gamma] enhances the antifibrotic effects of pirfenidone by attenuating IPF lung fibroblast activation and differentiation. Respir Res 2019, 20:206

96. Vancheri C, Kreuter M, Richeldi L, Ryerson CJ, Valeyre D, Grutters JC, Wiebe S, Stansen W, Quaresma M, Stowasser S, Wuyts WA; INJOURNEY Trial Investigators: Nintedanib with addon pirfenidone in idiopathic pulmonary fibrosis. Results of the INJOURNEY trial. Am J Respir Crit Care Med 2018, 197:356-363 